\title{
Impact of Bee Species and Plant Density on Alfalfa Pollination and Potential for Gene Flow
}

\author{
Johanne Brunet and Christy M. Stewart \\ USDA-Agricultural Research Service, Vegetable Crops Research Unit, Department of Entomology, 1630 Linden Drive, \\ University of Wisconsin, Madison, Wisconsin 53706, USA \\ Correspondence should be addressed to Johanne Brunet, jbrunet@wisc.edu
}

Received 15 September 2009; Accepted 1 December 2009

Academic Editor: James C. Nieh

Copyright ( $\odot 2010$ J. Brunet and C. M. Stewart. This is an open access article distributed under the Creative Commons Attribution License, which permits unrestricted use, distribution, and reproduction in any medium, provided the original work is properly cited.

\begin{abstract}
In outcrossing crops like alfalfa, various bee species can contribute to pollination and gene flow in seed production fields. With the increasing use of transgenic crops, it becomes important to determine the role of these distinct pollinators on alfalfa pollination and gene flow. The current study examines the relative contribution of honeybees, three bumble bee species, and three solitary bee species to pollination and gene flow in alfalfa. Two wild solitary bee species and one wild bumble bee species were best at tripping flowers, while the two managed pollinators commonly used in alfalfa seed production, honeybees and leaf cutting bees, had the lowest tripping rate. Honeybees had the greatest potential for gene flow and risk of transgene escape relative to the other pollinators. For honeybees, gene flow and risk of transgene escape were not affected by plant density although for the three bumble bee species gene flow and risk of transgene escape were the greatest in high-density fields.
\end{abstract}

\section{Introduction}

Different pollinators are expected to vary with respect to their relative role in the pollination of specific crops. Although managed pollinators are used for the pollination of large seed production fields of outcross bee-pollinated crops such as alfalfa, a number of wild pollinators also visit the flowers and participate in pollination [1-4]. Different insect pollinators have been shown to vary in how effectively they deposit and remove pollen from individual flowers $[5,6]$. For example, the tripping rate varies between bee species visiting alfalfa racemes $[1,7,8]$ and distinct species deposit different quantities of pollen on cranberry flowers during a single visit to a flower [2]. Such differences in tripping rates and pollen deposition can be influenced by whether a pollinator forages for pollen or for nectar [9] and has been shown to influence fruit and seed set $[2,7]$.

Pollinator type and landscape features can affect gene flow. Besides influencing pollination, distinct insect pollinators can also differentially affect gene flow or how genes are moved around the landscape [10]. In the Rocky Mountain columbine, pollen carried by bumble bees was more likely to sire seeds when it moved shorter distances but this was not the case for pollen carried by hawkmoths [10]. In addition to pollinator type, different features of the landscape can affect gene flow. For example, increasing plant density has been shown to reduce gene flow as pollinators respond to locally abundant floral resources and shorten their flight distances [11-13]. The pollen load carried by a pollinator between pollen donors and recipients is expected to turn over more rapidly as a pollinator visits a greater number of plants per unit distance traveled. This in turn reduces gene flow. In alfalfa, gene flow has been shown to be less in larger commercial fields relative to smaller experimental fields [14]. However, we know little about whether distinct insect pollinators react differentially to these various landscape attributes and whether these different responses affect pollen dispersal.

As commercial use of transgenic crops increases, it becomes important to determine the impact of distinct insect pollinators on gene flow, especially in outcrossing crops like alfalfa where various wild insect pollinators can contribute 
to the pollination and movement of alfalfa pollen $[1,4,15]$. Cresswell et al. [16] have developed a model to predict gene flow between transgenic and conventional fields in agriculture. Their model predicts that the number of flowers that a bee visits in a patch during one foraging bout, that is, the mean residence, estimates the extent to which transgenic pollen is diluted by conventional pollen [16]. In fact, the relative amount of transgenic pollen on the conventional field's flowers is inversely proportional to the total amount of pollen delivered by each bee during a bout of foraging in the conventional field [17]. Therefore the more flowers that a given pollinator visits per foraging bout, the smaller the relative amount of transgenic pollen and proportion of fruits set from transgenic pollen by that pollinator [17].

In the current study, we examine the impact of pollinator species and plant density on pollination and potential for gene flow in alfalfa, Medicago sativa. We compare the behavior of honeybees, three species of bumble bees, and three species of solitary bees visiting alfalfa flowers in patches planted at two different densities. As a measure of pollination, we compare the number of flowers visited per raceme, the number of flowers tripped per raceme, and the percentage of open flowers visited and tripped by the different pollinator types in patches planted at two densities. As a measure of the potential for gene flow, we compare the mean residence for each pollinator at the two planting densities. This study examines the relative contribution of distinct bee species to pollination and gene flow in alfalfa and determines whether and how distinct bee species are affected by plant density, a feature of the landscape known to influence gene flow.

\section{Materials and Methods}

2.1. Study Species. Medicago sativa (Fabaceae) is a perennial herb cultivated throughout the world mainly as a forage crop. In the United States, seed production occurs in California using honeybees (Apis mellifera) as managed pollinators and in the Pacific Northwest using mainly alfalfa leafcutting bees (Megachile rotundata). An alfalfa plant produces racemes of small perfect flowers typically ranging in color from pale to dark purple. The flowers require bee visitation for pollination. When a bee opens the keel petals, the enclosed stamen and pistil snap forward, forcefully striking the bee. Honeybees foraging for nectar soon learn to avoid this mechanism by approaching the flower from the side and inserting their proboscides through the petals near the base of the flower to reach the nectar (nectar thieves).

2.2. Experimental Setup and Data Collection. This study was conducted at West Madison Agricultural Research Station in Madison, WI, USA. In the spring of 2008, eight patches of 121 alfalfa plants were planted with four replicates at each of two densities: one plant every $0.3 \mathrm{~m}(3 \mathrm{~m} \times 3 \mathrm{~m}$ plot $)$, and one plant every $0.9 \mathrm{~m}(9 \mathrm{~m} \times 9 \mathrm{~m}$ plot $)$. Patches were laid out linearly with $3 \mathrm{~m}$ between patches, alternating between high and low density patches for a total of 968 alfalfa plants in the experiment. These densities represent $1 / 2$ and 2 times the density typically used for commercial alfalfa seed production.

In mid-June 2009, a hive of bumblebees (Bombus impatiens) and a hive of honeybees (Apis mellifera) were set up near the alfalfa plots. Five nesting blocks for alfalfa leafcutting bees (Megachile rotundata) were placed throughout the field, and alfalfa leafcutting bees were released periodically throughout the study period. When many alfalfa plants were in bloom, from late June to late July, one to three observers examined the behavior of the diverse bee species visiting alfalfa flowers. The observers noted plant density in the patch and recorded the insect species at a raceme, the number of open flowers visited and the number of flowers tripped at a raceme and counted the total number of open flowers on the raceme. A two-way analysis of variance with bee species and plant density as main factors and their twoway interaction (proc GLM, SAS, version 9.2) helped to determine the impact of bee species and plant density on the number of flowers visited per raceme, the number of flowers tripped per raceme, the proportion of open flowers visited per raceme, and the proportion of visited flowers that were tripped. Differences within a main factor were examined using Duncan's multiple range tests. Proportions were arcsine transformed prior to analyses to stabilize the variance. Graphs were drawn from the untransformed values.

To examine the potential impact of bumble bees and honeybees on gene flow, the border of a patch was observed: when a bumble bee or honeybee bee was spotted entering the patch, the bee was followed until it left the patch and the number of flowers it visited in the patch was tallied. Solitary bees proved too difficult to follow through the patch and therefore data on the number of flowers visited per patch could not be gathered for these bee species. The number of flowers visited per patch was recorded for the various bee species in the different patches and the impact of bee species and plant density on the number of flowers visited per patch during a foraging bout was examined using a twoway analysis of variance with bee species and plant density as main factors and their two- way interaction (proc GLM, SAS, version 9.2).

\section{Results}

3.1. Insect Visitors. Besides B. impatiens, A. mellifera, and $M$. rotundata, we commonly observed two species of wild bumble bees, B. griseocollis and B. auricomus, and two species of wild solitary bees, Halictus rubicundus and Andrena asteris visiting alfalfa flowers.

\subsection{Effects of Bee Species and Plant Density on Pollination.} The number of flowers visited per raceme, the proportion of open flowers visited on a raceme, the number of flowers tripped on a raceme, and the proportion of visited flowers that were tripped (tripping rate), were each affected by bee species $(P<.05)$ but not by plant density (Table 1$)$. Thus, bee species but not plant density affected the potential for pollination. However, the relative ranking of the different 
TABLE 1: Analysis of variance with pollinator species and plant density on (a) the number of flowers visited per raceme; (b) the number of flowers tripped per raceme; (c) the proportion of open flowers that were visited per raceme; (d) the proportion of visited flowers that were tripped per raceme.

\begin{tabular}{|c|c|c|c|c|c|}
\hline \multicolumn{6}{|c|}{ (a) Number of flowers visited per raceme } \\
\hline Source & d.f. & Sum-of-squares & MS & $F$-ratio & $P$ \\
\hline Bee species & 6 & 229.20 & 38.20 & 9.77 & $<.0001$ \\
\hline Plant density & 1 & 9.89 & 9.89 & 2.53 & .11 \\
\hline Bee* Density & 6 & 17.10 & 2.85 & 0.73 & .63 \\
\hline \multicolumn{6}{|c|}{ (b) Number of flowers tripped per raceme } \\
\hline Source & d.f. & Sum-of-squares & MS & $F$-ratio & $P$ \\
\hline Bee species & 6 & 170.47 & 28.41 & 13.01 & $<.0001$ \\
\hline Plant density & 1 & 4.99 & 4.99 & 2.29 & .13 \\
\hline Bee* Density & 6 & 17.40 & 2.9 & 1.33 & .24 \\
\hline \multicolumn{6}{|c|}{ (c) Proportion of open flowers that were visited } \\
\hline Source & d.f. & Sum-of-squares & MS & $F$-ratio & $P$ \\
\hline Bee species & 6 & 3.10 & 0.52 & 3.86 & .0009 \\
\hline Plant density & 1 & 0.0007 & 0.0007 & 0.01 & .94 \\
\hline Bee* Density & 6 & 0.84 & 0.14 & 1.05 & .39 \\
\hline \multicolumn{6}{|c|}{ (d) Proportion of visited flowers that were tripped } \\
\hline Source & d.f. & Sum-of-squares & MS & $F$-ratio & $P$ \\
\hline Bee species & 6 & 49.94 & 8.32 & 24.27 & $<.0001$ \\
\hline Plant density & 1 & 0.14 & 0.14 & 0.42 & .52 \\
\hline Bee* Density & 6 & 3.28 & 0.55 & 1.59 & .15 \\
\hline
\end{tabular}

TABLE 2: The relative rank of Bee species with respect to the number of flowers visited per raceme; the number of flowers tripped per raceme; the proportion of open flowers that were visited per raceme and the proportion of visited flowers that were tripped per raceme.

\begin{tabular}{lcccc}
\hline Bee species & No. of flowers visited & No. of flowers tripped & \% open flowers visited & \% visited flowers tripped \\
\hline B. griseocollis & 1 & 5 & 2 & 1 \\
B. auricomus & 2 & 1 & 4 & 3 \\
B. impatiens & 3 & 4 & 7 & 4 \\
A. asteris & 4 & 2 & 5 & 2 \\
H. rubicundus & 5 & 3 & 6 & 6 \\
A. mellifera & 6 & 7 & 3 & 5 \\
M. rotundata & 7 & 6 & 5
\end{tabular}

bee species depended on the specific variable under consideration (Table 2). For example, the three bumble bee species visited the most flowers per raceme and visited significantly $(P<.05)$ more flowers relative to the solitary bees and the honeybees (Figure 1(a)). On the other hand, the proportion of flowers visited per raceme was not as distinct between bee species (Figure 1(b)); most bee species visited fewer than half of the open flowers on a raceme on average (33-49\%) and B. auricomus visited $58 \%$ of the open flowers (Figure 1(b)). One of the wild bumble bee species, $B$. auricomus, and the two wild solitary bee species, A. asteris and $H$. rubicundus, tripped significantly more flowers than the other bee species (Figure 1(c)). Interestingly, the wild solitary bee species tripped on average over $80 \%$ of the flowers visited while the leaf cutting bees and honeybees only tripped $25 \%$ or fewer of the flowers visited per raceme in this study (Figure 1(d)). The number of flowers tripped per raceme depended on both the number of flowers visited per raceme and the proportion of these visited flowers that were tripped by the pollinators. Although they did not visit quite as many flowers per raceme as some of the other bee species, the tripping rate of the two wild solitary bee species was the highest and therefore together with $B$. auricomus, these two bee species tripped more flowers per raceme relative to the remaining pollinators.

3.3. Effects of Bee Species and Plant Density on Potential for Gene Flow. Bee species, plant density, and their interaction all significantly affected the number of flowers visited per patch during one foraging bout (Table 3). All three species of bumble bees visited more flowers in low relative to high density patches, while honeybees were not influenced by plant density (Figure 2). Bumble bees visited more flowers per patch relative to honeybees and B. impatiens visited fewer flowers per patch relative to the other two bumble bee species, especially in low density patches (Figure 2). 


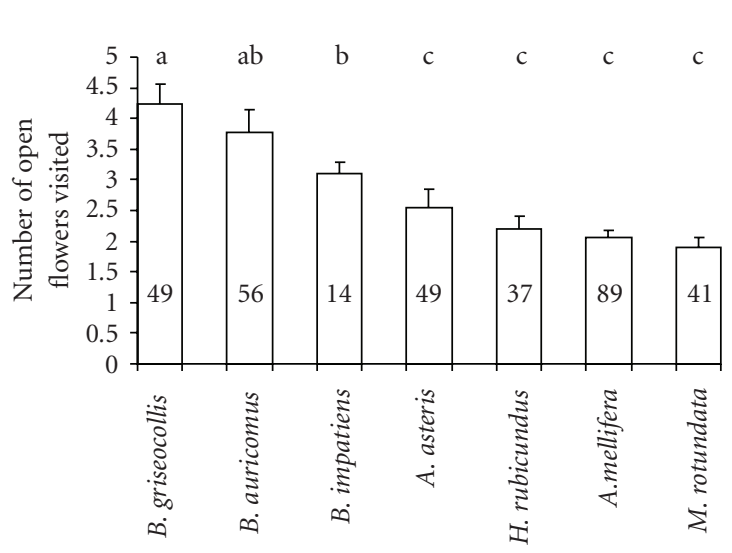

(a) Bee species and number of flowers visited

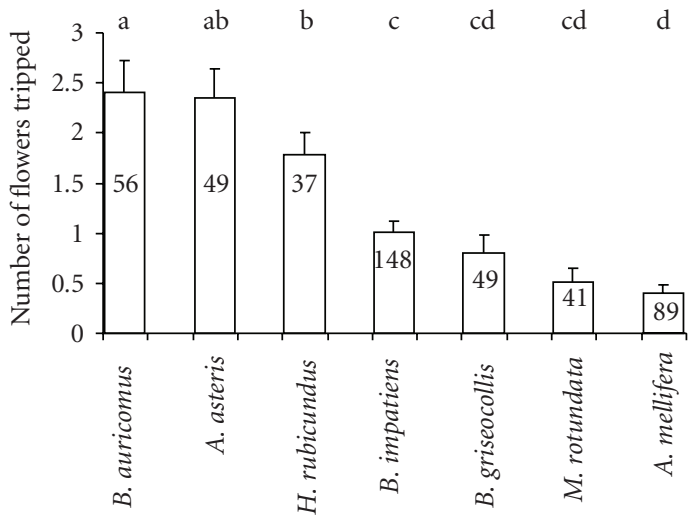

(c) Bee species and number of flowers tripped

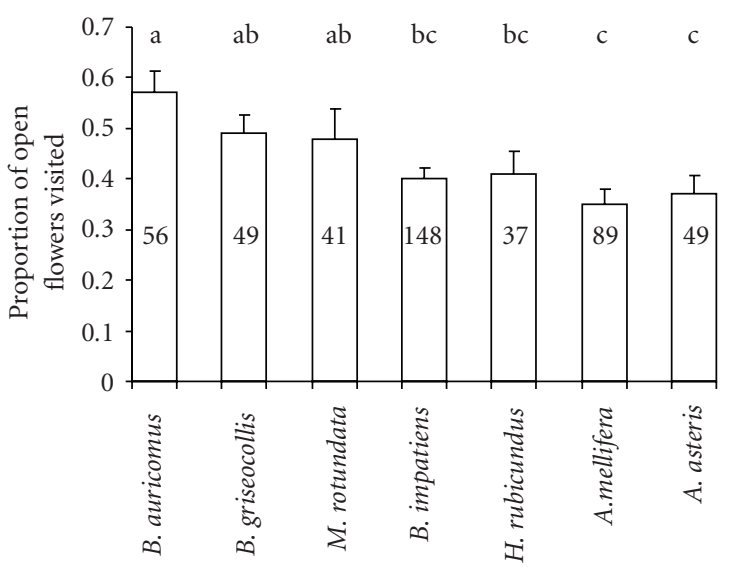

(b) Bee species and proportion of open flowers visited

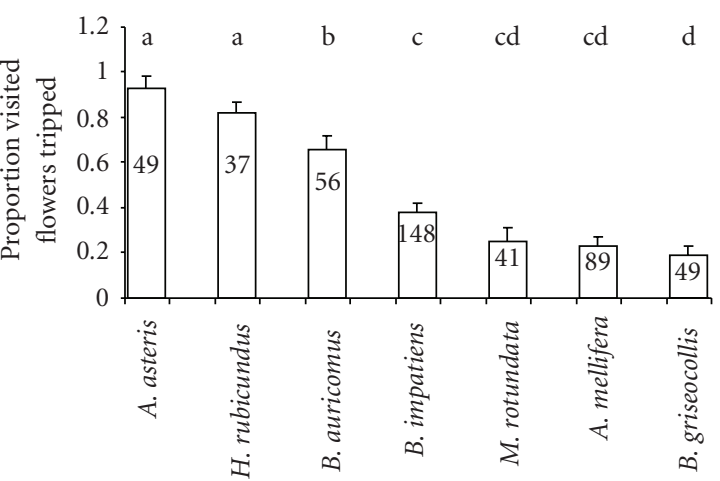

(d) Bee species and proportion of visited flowers that were tripped

FIgURE 1: The impact of bee species on (a) the number of flowers visited per raceme; (b) the number of flowers tripped per raceme; (c) the proportion of open flowers that were visited per raceme; $(d)$ the proportion of visited flowers that were tripped per raceme. The numbers inside each column represent the sample sizes while different letters indicate a statistically significant difference between bee species as determined by the Duncan's multiple range test.

TABLE 3: Analysis of variance with pollinator species and plant density on the number of flowers visited per patch during one foraging bout by bumble bees and honeybees.

\begin{tabular}{lccccc}
\hline Source & d.f. & Sum-of-squares & MS & $F$-ratio & 3.92 \\
\hline Bee species & 3 & 258071.2 & 86023.7 & 321828.9 & 14.68 \\
Plant density & 1 & 321828.9 & 65826.3 & 3.00 & .0002 \\
Bee* Density & 3 & 197478.8 & .0307 \\
\hline
\end{tabular}

\section{Discussion}

4.1. Effects of Bee Species on Pollination. The distinct bee species differentially affected pollination. The two wild solitary bees, $A$. asteris and $H$. rubicundus, had the highest tripping rate followed by one wild bumble bee species, $B$. auricomus. Together these three bee species tripped the most flowers per raceme. The leaf cutting bees, honeybees, and one of the wild bumble bee species, B. griseocollis, had the lowest tripping rate and tripped the lowest number of flowers per raceme. Variation in tripping rate between bee species visiting alfalfa flowers has been reported previously $[1,7,8]$. In caged enclosures or in the greenhouse, female leaf cutting bees and alkali bees, Nomia melanderi, have tripped close to $80 \%$ of the visited flowers $[7,8]$. Lower tripping rates (51\%) have been associated with male leaf cutting bees [7]. However, under field conditions, the tripping rate of leaf cutting bees can vary over the growing season [18]. In Oregon, tripping rates of $10 \%$ were detected during the first three weeks of alfalfa blooming and this rate increased sharply to over $80 \%$ later in the season, presumably as females became fully established (nesting females) in the 


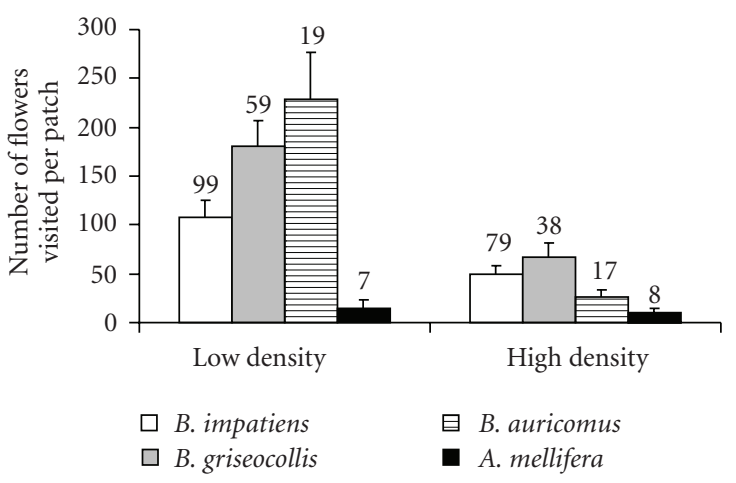

Figure 2: The impact of bee species and plant density on the number of flowers visited per patch during one foraging bout.

field [18]. In the current experiment, leaf cutting bees were released in the field throughout the alfalfa flowering period. The presence of males in the samples and the cooler temperatures in Madison in summer 2009 may help explain the low tripping rates observed for leaf cutting bees in this study because higher temperatures are known to ease the tripping of flowers by bees $[1,7,10,19]$. Tripping rates of honeybees have been well studied and tend to be low (reported between 2 and 22\%) unless temperatures are very high $[1,7]$. The low tripping rate of honeybees results from the fact that honeybees quickly learn to work a flower from the side in order to avoid the tripping mechanism [20]. In this study, two of the pollinators that are used on a commercial scale to pollinate alfalfa flowers, honeybees and leaf cutting bees, had some of the lowest tripping rates and number of flowers tripped per visit to a raceme.

The differences in tripping rates and number of flowers tripped per raceme between the three bumble bee species were not related to tongue length where longer tongues would allow the species to collect nectar without tripping the flowers [1]. The species B. griseocollis and B. impatiens have similar tongue lengths [21] and shorter tongues relative to $B$. auricomus. All three species were observed collecting nectar and had pollen sacs which suggest that both nectar and pollen were being collected from alfalfa flowers. The efficiency of wild solitary bees at tripping alfalfa flowers has been reported in other studies (summarized in [1]). Although we only examined tripping rates and did not collect corresponding data on subsequent fruit and seed set, Cane [7] has shown that tripping rate was a reliable relative measure of pollination when comparing different bee species. In his study, Cane [7] demonstrated that bee species and sexes did not differ in the proportions of tripped flowers that set pods and that on average $45-54 \%$ of pollinated flowers set fruits in alfalfa.

Tripping rate is only one of the variables affecting the efficiency of bee species as pollinators of alfalfa flowers. The number of flowers tripped per visit to a raceme is also important and depends on the number of flowers visited per raceme, a variable that has been shown to vary between bee species in the current study. However, increasing the number of flowers visited per raceme may also increase the level of geitonogamous selfing (selfing among flowers on a plant) $[22,23]$. Because inbreeding depression is significant in alfalfa (selfed progenies have decreased vigor and seed productivity [1]), a bee species that visits a large number of flowers per plant could negatively impact yield. In addition, visited flowers that have not been tripped but whose nectar has been depleted may lower subsequent visitation rate and pollination success while also increasing the cost of pollination in term of nectar production to the flowers. Nectar robbing has been shown to decrease fruit and seed set of plants in some plant species $[24,25]$ although the impact on plant reproductive success is not always negative [26]. It would be interesting in future studies to determine how the proportion of nectar thieves in a field (pollinators that collect nectar but do not trip the flowers) affects nectar production, visitation rates to alfalfa flowers, and fruit and seed set (yield).

In the current study, we measured the impact of a pollinator visit to a raceme. Ultimately, the abundance and visitation rate of the different bee species together with the number of flowers each pollinator trips per visit to a raceme determine their impact on pollination of alfalfa flowers [17]. A more abundant pollinator that trips fewer flowers per raceme per visit may have the same impact on pollination as a less abundant pollinator that trips a greater number of flowers per visit to a raceme. Similarly, a pollinator that is abundant in the area but has lower visitation rate to alfalfa flowers may have a similar impact on alfalfa pollination as a less abundant pollinator that has a high frequency of visits to alfalfa flowers. Finally, pollinator species may interfere with one another, as would be the case if a pollinator species with a low tripping rate of flowers depleted nectar from flowers and affected future visitations by pollinators with high tripping rates. Although this study was not designed to measure relative visitation rates or pollinator abundance, our sample sizes for visits to inflorescences and for number of flowers visited per patch indicate common visits by wild bee species to alfalfa flowers.

This study, together with previous work on alfalfa $[1,4]$, highlights the efficiency of wild pollinators for pollination of alfalfa flowers. In fact, wild bees were utilized as pollinators for leguminous crops in vast areas of the U.S. about 100 years ago [4]. However, increases in field sizes and use of insecticides and decreases in natural habitats around agricultural fields have reduced the use of wild pollinators in alfalfa and other leguminous crop pollination [4]. Current problems in maintaining sufficiently large populations of leaf cutting bees in the fields, combined with the fact that we rely on Canadian sources of bees with few alternative sources of leaf cutting bees in the event of catastrophes [20], strongly emphasize the need for the development of management practices that encourage and facilitate the establishment of wild bumble bees and solitary bees around alfalfa seed production fields. Although the goal should not be to rely entirely on wild pollinators for pollination of large alfalfa production areas, the presence of wild pollinators would decrease the risks associated with strictly relying on leaf cutting bees and could reduce the high price currently associated with alfalfa pollination. 
4.2. Effects of Bee Species and Plant Density on Potential for Gene Flow. In alfalfa, plant density affected gene flow by insect pollinators but not all pollinators had the same response to a change in plant density. Although all bumble bee species visited more flowers per foraging bout in low relative to high density patches, honeybees were not affected by plant density and visited the same number of flowers in high and low density patches. Honeybees visited few flowers per patch irrespective of plant density. If the relative amount of transgenic pollen in the conventional field's flowers is inversely proportional to the total amount of pollen delivered by each bee during a bout of foraging in the conventional field as suggested by Cresswell [17], then the lower mean residence of the honeybees would suggest a higher relative transfer of transgenic pollen by honeybees relative to the other pollinators. The results obtained in this study imply that the higher transfer of transgenic pollen by honeybees would not be affected by plant density. These data suggest that honeybees may represent a greater risk of transgene escape relative to the bumble bee pollinators observed in this study. However, greater sample sizes for honeybees would be useful to confirm the trends reported here.

The lower mean residence observed at high relative to low density for all bumble bee species suggests a greater risk of transgene escape at high relative to low density for bumble bees. This pattern runs opposite to what had been observed in a previous study where increasing density decreased gene flow [11]. In this previous study, increasing plant density shortened flight distances between plants [12]. High density situations often do shorten intermate distances which tend to reduce dispersal distance $[13,27,28]$ because it induces higher pollen turnover within shorter distances. However, in our system, all three species of bumble bees consistently visited more flowers per foraging bout in low density patches. In the high density treatment, plants were intertwined which would tend to limit the growth of each individual plant. Increasing plant density may lower gene flow up to a point but then increase it when plant growth becomes limited. This situation commonly occurs in agricultural field settings and therefore deserves further investigation. Future work is needed to clarify the impact of density on gene flow by insect pollinators. The fact remains, however, that except for honeybees, plant density influenced gene flow by insect pollinators in this study.

Our findings support previous studies by demonstrating differences in pollination efficiency of alfalfa flowers by distinct bee species. Our results also highlight the efficiency of many wild bee species as pollinators of alfalfa. Therefore, encouraging the establishment of wild bee species around commercial fields of alfalfa seed production fields could reduce the risks and the costs associated with our reliance on a single managed pollinator like the leaf cutting bee. However, with the potential increase in commercial production of transgenic alfalfa, it is also important to determine the potential impact of these distinct pollinators on gene flow. Here we demonstrate that distinct pollinators can have different potential impact on gene flow and risk of transgene escape and that not all pollinators respond similarly to changes in plant density, a feature of the landscape known to influence gene flow. The impact of pollinator species on gene flow and risk of transgene escape will ultimately depend not only on the number of flowers visited per foraging bout in a patch but also on the absolute and relative abundance of the different pollinator species in the alfalfa field. We have a lot more to learn about the potential impact of wild pollinators on pollination, gene flow, and risk of transgene escape in outcross insect-pollinated crops but this study represents a first step in that direction.

\section{Acknowledgments}

The authors are grateful to Zachary Larson-Rabin for his help with setting up the alfalfa plots and raising the leaf cutting bees. A. Johnson helped with pollinator observations and S. Krauth with pollinator identification. Andrew Bonde provided the honeybee hive used in this experiment. Funding to the first author was provided by the United States Department of Agriculture, Agricultural Research Service.

\section{References}

[1] G. E. Bohart, "Pollination of alfalfa and red clover," Annual Review of Entomology, vol. 2, pp. 355-380, 1957.

[2] J. H. Cane and D. Schiffhauer, "Dose-response relationships between pollination and fruiting refine pollinator comparisons for cranberry (Vaccinium macrocarpon [Ericaceae])," American Journal of Botany, vol. 90, no. 10, pp. 1425-1432, 2003.

[3] K. E. Hayter and J. E. Cresswell, "The influence of pollinator abundance on the dynamics and efficiency of pollination in agricultural Brassica napus: implications for landscape-scale gene dispersal," Journal of Applied Ecology, vol. 43, no. 6, pp. 1196-1202, 2006.

[4] S. Cecen, F. Gurel, and A. Karaca, "Impact of honeybee and bumblebee pollination on alfalfa seed yield," Acta Agriculturae Scandinavica Section B, vol. 58, no. 1, pp. 77-81, 2008.

[5] P. Wilson and J. D. Thomson, "Heterogeneity among floral visitors leads to discordance between removal and deposition of pollen," Ecology, vol. 72, pp. 1503-1507, 1991.

[6] J. D. Thomson and K. Goodell, "Pollen removal and deposition by honeybee and bumblebee visitors to apple and almond flowers," Journal of Applied Ecology, vol. 38, no. 5, pp. 10321044, 2001.

[7] J. H. Cane, "Pollinating bees (Hymenoptera: Apiformes) of U.S. alfalfa compared for rates of pod and seed set," Journal of Economic Entomology, vol. 95, no. 1, pp. 22-27, 2002.

[8] S. W. T. Batra, "Comparative efficiency of alfalfa pollination by Nomia melanderi, Megachile rotundata, Anthidium florentinum and Pithitis smaragdula (Hymenoptera: Apoidea)," Journal of the Kansas Entomological Society, vol. 49, pp. 18-22, 1976.

[9] H. J. Young, D. W. Dunning, and K. W. von Hasseln, "Foraging behavior affects pollen removal and deposition in Impatiens capensis (Balsaminaceae)," American Journal of Botany, vol. 94, no. 7, pp. 1267-1271, 2007.

[10] J. Brunet and K. G. A. Holmquist, "The influence of distinct pollinators on female and male reproductive success in the Rocky Mountain columbine," Molecular Ecology, vol. 18, no. 17, pp. 3745-3758, 2009. 
[11] R. S. Manasse, "Ecological risks of transgenic plants: effects of spatial dispersion on gene flow," Ecological Applications, vol. 2, no. 4, pp. 431-438, 1992.

[12] W.F. Morris, "Predicting the consequences of plant spacing and biased movement for pollen dispersal by honey bees," Ecology, vol. 74, no. 2, pp. 493-500, 1993.

[13] F. Ishihama, S. Ueno, Y. Tsumura, and I. Washitani, "Effects of density and floral morph on pollen flow and seed reproduction of an endangered heterostylous herb, Primula sieboldii," Journal of Ecology, vol. 94, no. 4, pp. 846-855, 2006.

[14] P. C. St. Amand, D. Z. Skinner, and R. N. Peaden, "Risk of alfalfa transgene dissemination and scale-dependent effects," Theoretical and Applied Genetics, vol. 101, no. 1-2, pp. 107$114,2000$.

[15] A. E. Van Deynze, S. Firzpatrick, B. Hammon, et al., Gene Flow in Alfalfa: Biology, Mitigation, and Potential Impact on Production, Council for Agricultural Science and Technology, Ames, Iowa, USA, 2008.

[16] J. E. Cresswell, J. L. Osborne, and S. A. Bell, "A model of pollinator-mediated gene flow between plant populations with numerical solutions for bumblebees pollinating oilseed rape," Oikos, vol. 98, no. 3, pp. 375-384, 2002.

[17] J. E. Cresswell, "Estimating the potential for bee-mediated gene flow in genetically modified crops," in Bee Pollination in Agricultural Ecosystems, R. R. James and T. L. Pitts-Singer, Eds., pp. 184-202, Oxford University Press, New York , NY, USA, 2009.

[18] J. Bosch and W. P. Kemp, "Alfalfa leafcutting bee population dynamics, flower availability, and pollination rates in two Oregon alfalfa fields," Journal of Economic Entomology, vol. 98, no. 4, pp. 1077-1086, 2005.

[19] D. Breazeale, G. Fernandez, and R. Narayanan, "Modeling pollination factors that influence alfalfa seed yield in northcentral Nevada," Journal of Central European Agriculture, vol. 9, no. 1, pp. 107-115, 2008.

[20] T. L. Pitts-Singer, "Past and present management of alfalfa bees," in Bee Pollination in Agricultural Systems, R. R. James and T. L. Pitts-Singer, Eds., pp. 105-123, Oxford University Press, New York, NY, USA, 2008.

[21] B. Zorn-Arnold and H. F. Howe, "Density and seed set in a self-compatible forb, Penstemon digitalis (Plantaginaceae), with multiple pollinators," American Journal of Botany, vol. 94, no. 10, pp. 1594-1602, 2007.

[22] L. D. Harder and S. C. H. Barrett, "Mating cost of large floral displays in hermaphrodite plants," Nature, vol. 373, no. 6514, pp. 512-515, 1995.

[23] J. D. Karron, R. J. Mitchell, K. G. Holmquist, J. M. Bell, and B. Funk, "The influence of floral display size on selfing rates in Mimulus ringens," Heredity, vol. 92, no. 3, pp. 242-248, 2004.

[24] R. E. Irwin and A. K. Brody, "Nectar-robbing bumble bees reduce the fitness of Ipomopsis aggregata (Polemoniaceae)," Ecology, vol. 80, no. 5, pp. 1703-1712, 1999.

[25] L. Navarro and R. Medel, "Relationship between floral tube length and nectar robbing in Duranta erecta L. (Verbenaceae)," Biological Journal of the Linnean Society, vol. 96, no. 2, pp. 392398, 2009.

[26] J. E. Maloof and D. W. Inouye, "Are nectar robbers cheaters or mutualists?” Ecology, vol. 81, no. 10, pp. 2651-2661, 2000.

[27] D. A. Levin and H. Kerster, "Density-dependent gene dispersal in Liatris," The American Naturalist, vol. 103, pp. 61-74, 1969.

[28] C. García, J. M. Arroyo, J. A. Godoy, and P. Jordano, "Mating patterns, pollen dispersal, and the ecological maternal neighbourhood in a Prunus mahaleb L. population," Molecular Ecology, vol. 14, no. 6, pp. 1821-1830, 2005. 

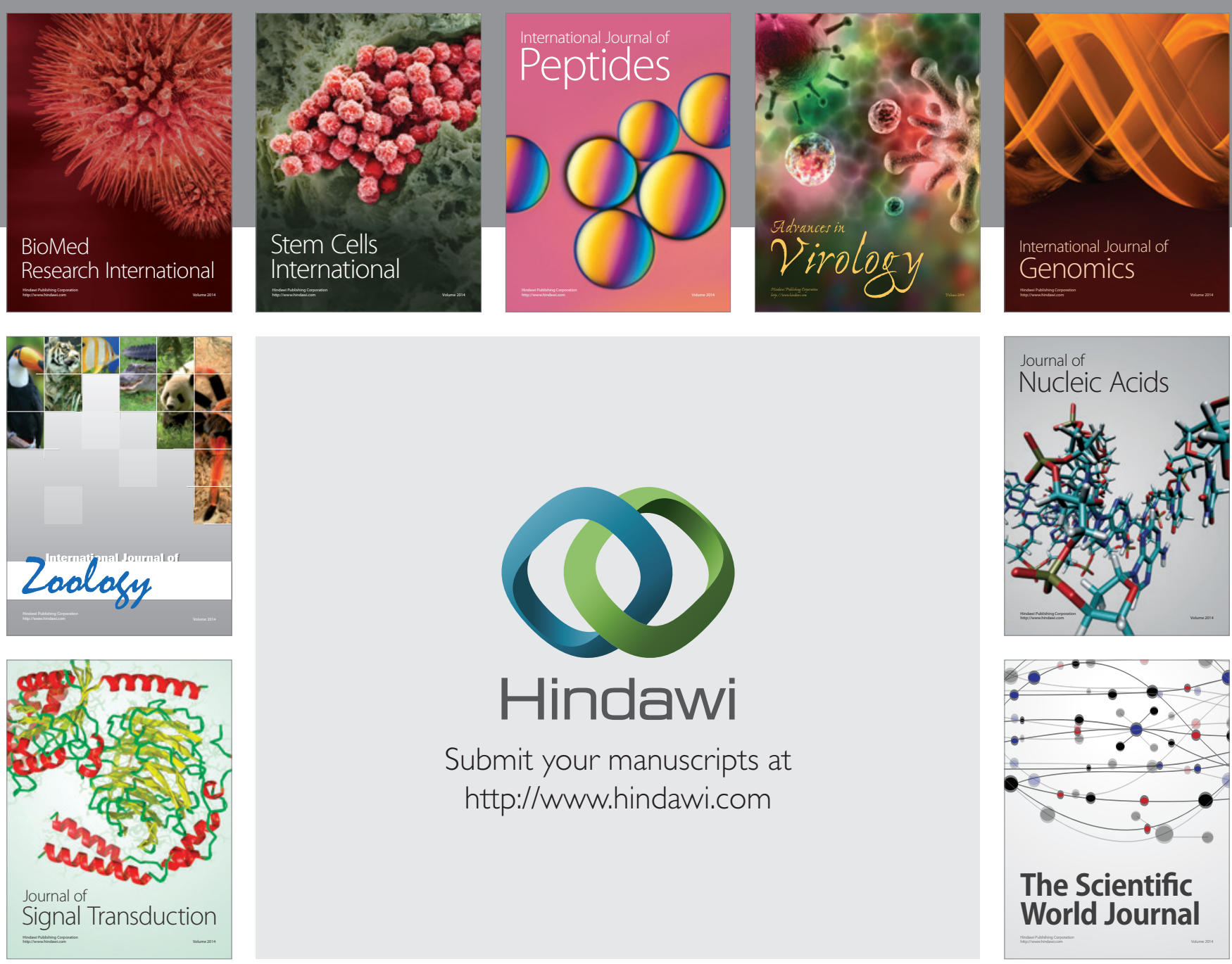

Submit your manuscripts at

http://www.hindawi.com
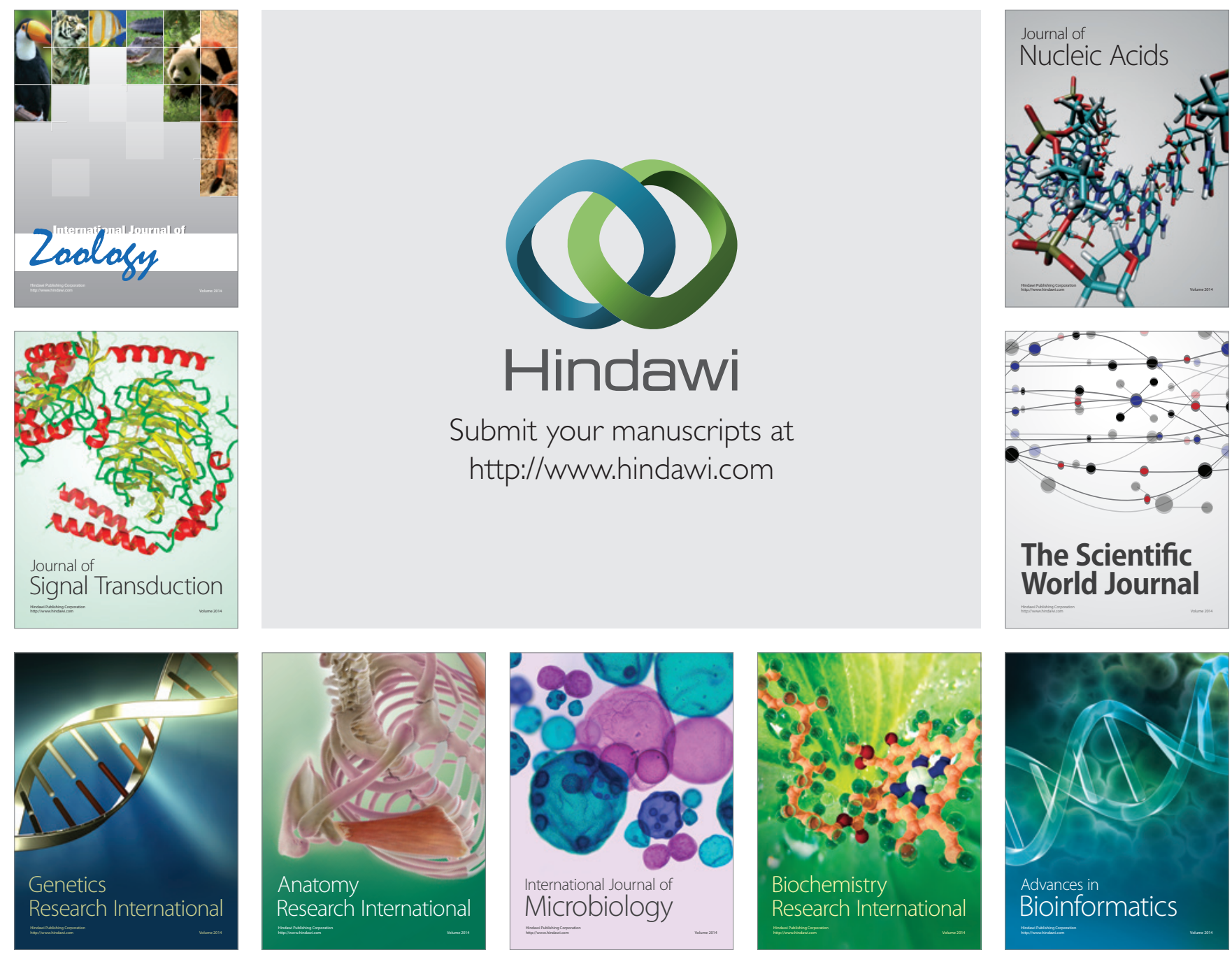

The Scientific World Journal
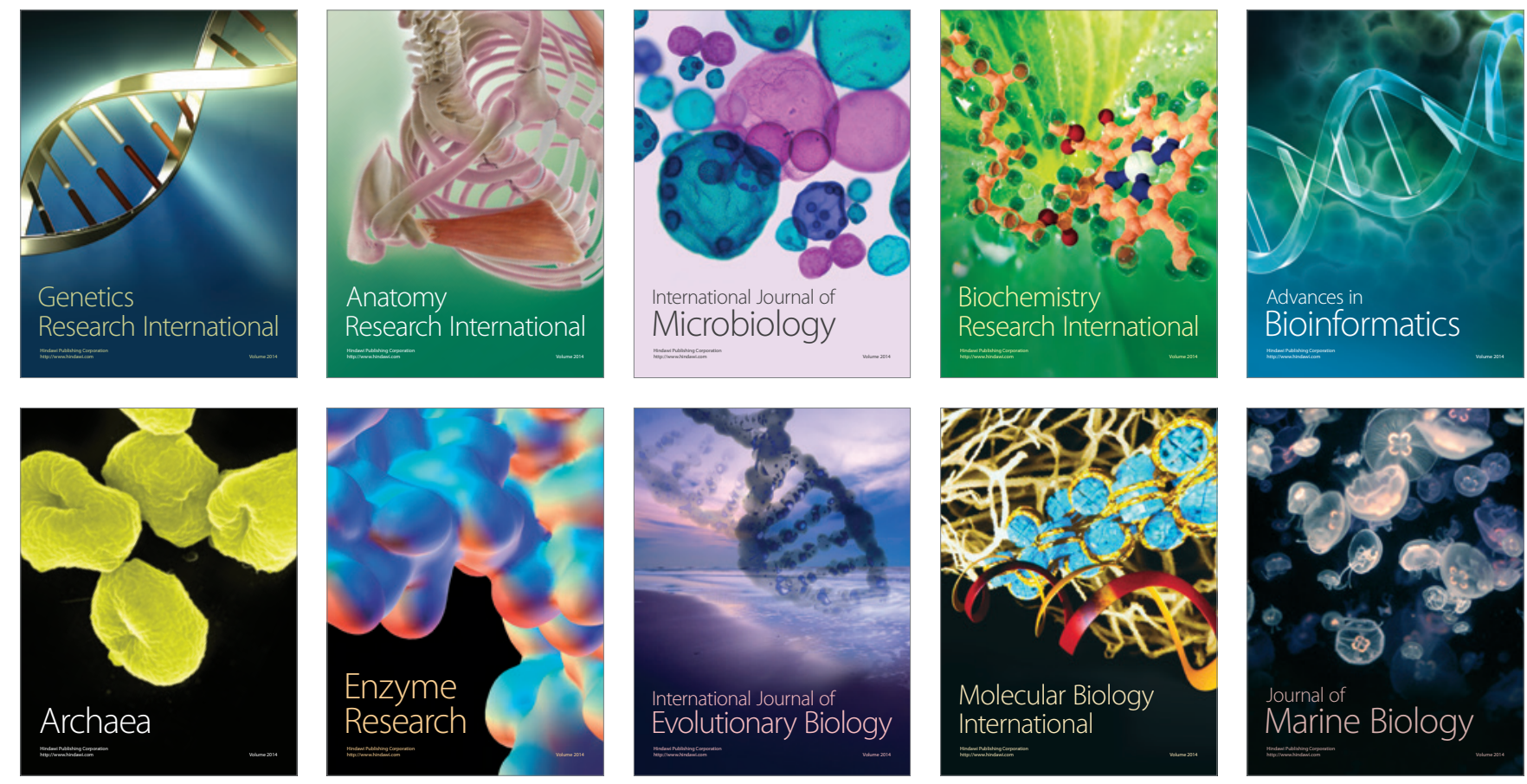